\author{
Marquette University \\ e-Publications@Marquette
}

College of Nursing Faculty Research and

Publications

Nursing, College of

$7-2012$

\title{
Resourcefulness Training Intervention: Assessing Critical Parameters from Relocated Older Adults' Perspectives
}

\author{
Abir K. Bekhet \\ Marquette University, abir.bekhet@marquette.edu \\ Jaclene Zauszniewski \\ Case Western Reserve University \\ Denise M. Matel-Anderson \\ Marquette University, denise.matel-anderson@marquette.edu
}

Follow this and additional works at: https://epublications.marquette.edu/nursing_fac

Part of the Nursing Commons

\section{Recommended Citation}

Bekhet, Abir K.; Zauszniewski, Jaclene; and Matel-Anderson, Denise M., "Resourcefulness Training Intervention: Assessing Critical Parameters from Relocated Older Adults' Perspectives" (2012). College of Nursing Faculty Research and Publications. 317.

https://epublications.marquette.edu/nursing_fac/317 
Marquette University

e-Publications@Marquette

\title{
Nursing Faculty Research and Publications/College of Nursing
}

This paper is NOT THE PUBLISHED VERSION; but the author's final, peer-reviewed manuscript. The published version may be accessed by following the link in the citation below.

Issues in Mental Health Nursing, Vol. 33, No. 7 (2012): 430-435. DOI. This article is (C) Taylor \& Francis and permission has been granted for this version to appear in e-Publications@Marquette. Taylor \& Francis does not grant permission for this article to be further copied/distributed or hosted elsewhere without the express permission from Taylor \& Francis.

\section{Resourcefulness Training Intervention: Assessing Critical Parameters from Relocated Older Adults' Perspectives}

\author{
Abir K. Bekhet \\ College of Nursing, Marquette University, Milwaukee, WI \\ Jaclene A. Zauszniewski \\ Bolton School of Nursing, Case Western Reserve University, Cleveland, $\mathrm{OH}$ \\ Denise M. Matel-Anderson \\ College of Nursing, Marquette University, Milwaukee, WI
}

\begin{abstract}
The population of American elders is increasing rapidly and relocation to retirement communities has been found to adversely affect their adjustment. This pilot study of 38 relocated elders evaluated, from elders' perspectives, six critical parameters of a resourcefulness training (RT) intervention designed to help elders adjust to relocation. Within the context of Zauszniewski's theory of resourcefulness, a pre-
\end{abstract}


/post-test design with random assignment to RT or to diversionary activities (DA) was used. Objective questionnaires measured demographic and relocation factors. An intervention evaluation questionnaire was designed and given to the relocated elders in order to assess the six critical parameters - necessity, acceptability, feasibility, safety, fidelity, and effectiveness. Data concerning the critical parameters were collected during structured interviews within a week after the intervention. Seventy-six of the elders who scored less than 120 in the resourcefulness scale indicated a strong need for RT. While all non-white elders reported needing RT, $43 \%$ of white elders reported the same need. Elders indicated that learning about the experiences of others and taking part in discussions were the most interesting part of the RT. Approximately $95 \%$ of participants mentioned that they learned all parts of the intervention; few suggested having a stronger leader to keep the group on track. The qualitative findings from this pilot intervention study will inform future, larger clinical trials to help recently relocated elders adjust to relocation.

\section{BACKGROUND AND SIGNIFICANCE}

The population of older adults in the US is expected to reach 72 million by the year 2030 (US Department of Health and Human Services, Administration on Aging [AOA], 2011). Approximately, 80\% of older adults have at least one chronic condition and $50 \%$ have two or more (National Center for Chronic Disease Prevention and Health Promotion, 2011) that may interfere with their daily activities and adaptive functioning (Griffith, Raina, Wu, Zhu, \& Stathokostas, 2010; Wolff, Boult, Boyd, \& Anderson, 2005; Zauszniewski, Eggenschwiler, Preechawong, Roberts, \& Morris, 2006). Functional status might be affected by older adults' abilities to be resourceful. Indeed, research has shown that persons with high resourcefulness have more adaptive functioning, better self-assessed health (Zauszniewski \& Bekhet, 2011; Zauszniewski, Eggenschwiler et al., 2006), and better relocation adjustment (Bekhet, Zauszniewski, \& Wykle, 2008).

Resourcefulness is a collection of cognitive and behavioral skills that are used to attain, maintain, or regain health. Resourcefulness theory (Zauszniewski, 2006) suggests there are two types of resourcefulness: personal (self-help) and social (help-seeking) resourcefulness. Resourcefulness includes the ability to maintain independence in daily tasks despite potentially unfavorable situations (personal resourcefulness or self-help) (Rosenbaum, 1990; Zauszniewski, 2006) and to look for help from others when unable to function alone (social resourcefulness or help-seeking) (Nadler, 1990; Zauszniewski, 2006). The rapidly growing aging population in the US has led to the construction of 30,000 to 40,000 retirement communities that house approximately 1 million elderly residents (Bekhet, Zauszniewski, \& Nakhla, 2009; Chao, Hagsavas, Mollica, \& Dwyer, 2003). Although small group resourcefulness training has been tested in retirement communities, the authors reported that $9 \%$ of participants dropped out because of loss of interest in participating in groups (Zauszniewski, Eggenschwiler et al., 2006). However, that study did not examine the degree to which the elderly participants perceived the intervention as necessary, acceptable, feasible, or safe (Zauszniewski, 2012). Information on these parameters from elders' perspective, along with information on intervention fidelity and effectiveness, is needed to inform future resourcefulness training interventions for elders who have recently relocated to a retirement community. This pilot study, therefore, evaluated older adults' views of the acceptability, feasibility, safety, necessity, fidelity, and effectiveness of a 
resourcefulness training intervention (Zauszniewski, 2012) designed to help older adults have better adaptive functioning.

\section{METHODS}

\section{Design}

In this descriptive pilot study, qualitative data on the six intervention parameters-necessity, acceptability, feasibility, safety, fidelity, and effectiveness - were collected during face-to-face interviews immediately after the intervention.

\section{Procedure}

Prior to participant identification and recruitment, approval was obtained from the University Institutional Review Board. The researchers contacted the staff in the retirement communities to ask for their help in recruiting the study participants. Flyers containing the researchers contact information were distributed in the retirement communities. The researchers met with the residents in a conference room at an agreed upon time and explained the purpose of the study. Those who were interested were administered the Short Portable Mental Status Questionnaire (SPMSQ) to screen for cognitive deficits (Pfeiffer, 1975). The questionnaire items, as well as the intervention, required older adults to be cognitively intact. Four older adults who scored 7 or less were excluded from further participation. Others who were interested in participating and met the study criteria were interviewed and completed all the study questionnaires.

\section{Participants}

A convenience sample of 40 older adults who relocated to retirement communities was recruited from three retirement communities in Milwaukee, WI. The retirement communities were randomly assigned to the resourcefulness training (RT) intervention or control group. There were 20 elders in each of the two groups. Two participants dropped out of the study (one from the control group and one from the RT group), leaving 38 elders.

\section{The Intervention}

The RT intervention was provided in a small group format. Two intervention groups were formed; one intervention group had nine older adults and the other had ten. The group approach is preferable for older adults in retirement communities because they are accustomed to groups. Previous research has supported the success of group interventions with older adults in similar settings (Ayers, Sorrell, Thorp, \& Wetherell, 2007; Miller, 2008; Van't Veer-Tazelaar et al., 2009; Wilkinson et al., 2009). Thus, the small group format was considered optimal for delivering the resourcefulness training intervention to relocated elders. A group size of ten elders was found to be successful in a previous study of RT in elders in retirement facilities (Zauszniewski, 1997, 2006).

For the two resourcefulness training (RT) groups, one session was scheduled every week for six weeks, and each session lasted for $1 \frac{1}{2}$ hours. Older adults were taught the skills constituting resourcefulness, including coping strategies, problem solving, positive self-talk, priority setting, and decision making (Zauszniewski, 2006; Zauszniewski, Eggenschwiler et al., 2006). The intervention was conducted by a nurse clinician trained in the intervention. Instructional methods included group discussion and verbal instruction. 


\section{MEASURES AND INSTRUMENTS}

\section{Measuring and Evaluating the Intervention Parameters}

Necessity of the RT intervention was evaluated by asking the older adults if they thought they needed the intervention and if they thought that other elders who relocated to retirement communities would benefit from the intervention. Necessity also was determined by examining baseline scores on the resourcefulness scale; scores above 120) indicated less need for intervention (Zauszniewski, 2012).

Acceptability of the intervention was assessed by asking the older adults to describe what part or parts of the intervention were most, and least, interesting and whether they thought that the group format and intervention content were appropriate for them.

The feasibility of the intervention was evaluated by asking the older adults to describe what part or parts of the intervention were easiest, which were most challenging, and whether they thought that the number and length of the sessions were appropriate in terms of time commitment.

The fidelity of the intervention was assessed by asking the older adults whether they thought they learned all the skills constituting resourcefulness and what might have helped to learn them better. Fidelity also was assessed by examining scores on the Resourcefulness Scale since Resourcefulness scores would be expected to increase if the skills constituting resourcefulness were taught effectively.

The safety of the group intervention was evaluated by asking the older adults what part or parts of the intervention were most, and least, distressing or uncomfortable and whether they had any concerns about confidentiality during the group interactions.

Effectiveness of the resourcefulness intervention was assessed by asking the older adults what part or parts of the intervention were most, and least, helpful in teaching them to cope with their relocation. They also were asked to describe ways in which the intervention might be improved.

Resourcefulness was measured by the 28-item Resourcefulness Scale (RS) (Zauszniewski, Lai, \& Tithiphumturong, 2006). The Resourcefulness scale is a self-report scale that assesses an individual's tendencies to apply self-help and help-seeking behaviors when faced with adverse situations (Zauszniewski, Lai et al., 2006). The Resourcefulness scale consists of 16 items that measure personal resourcefulness and 12 items that measure social resourcefulness (Zauszniewski, Lai et al., 2006). A 6point scoring system, with response alternatives ranging from 0 (not at all like me) to 5 (very much like me), was used (Zauszniewski, Lai et al., 2006). Thus, total scores may range from 0 to 140, with higher scores indicating greater resourcefulness (Zauszniewski, Lai et al., 2006). Internal consistency for the Resourcefulness Scale has been estimated by Cronbach's alpha of $.83, .79$, and .85 for the total scale, and personal and social resourcefulness subscales, respectively (Zauszniewski, Lai et al., 2006). Evidence for construct validity was demonstrated by the emergence of the two dimensions of resourcefulness (personal and social) in a confirmatory factor analysis and substantial intercorrelation between the two subscales ( $r=.41, p<.001$ ) (Zauszniewski, Lai et al., 2006).

Degree of Environmental Change was measured by a scale from 1 to 10 , on which participants were asked to circle the number that corresponded to how close/ different they found this assisted living as compared to their former living situation. Choosing " 1 " indicated the current facility was less different and " 10 " indicated that it was very different. 
Perceived Health Status was measured by a single item index based on a 4-point Likert-type scale ranging from 1 (poor) to 4 (excellent), in which participants recorded their perception of their health. This index has been used in previous studies and is accepted as a valid indicator of the subjective appraisal of health status (Musil, Haug, \& Warner, 1998). Higher scores indicate better health.

\section{DATA ANALYSIS AND RIGOR OF THE RESEARCH}

The data obtained during the interviews with older adults were transcribed and themes were identified. Credibility of the data was enhanced by independent coding of the data by two researchers with a percentage agreement that exceeded $95 \%$ while comparing the coding schemes, the categorization, and the conceptual themes (Glaser, 1992; Streubert \& Carpenter, 1999). In addition, the use of quotations further enhanced the credibility and truthfulness of the research. Saturation was achieved as there was redundancy and as no new themes arose as more information was collected (Guba \& Lincoln, 1989).

\section{RESULTS}

\section{The Study Sample}

There were 29 women (76\%) and 9 men (24\%) who completed the study, and their ages ranged from 65 to 92 ( $M=78$ years). Ten participants were widowed (26\%), and another ten were married (26\%). Approximately $24 \%$ completed graduate school or had a college education, $50 \%$ had an associate degree, and $26 \%$ had a high school education or less. All residents (100\%) were living in an independent living facility. Eighty-two percent had transferred from home and $18 \%$ had transferred either from hospitals, other units, or other sites. Twenty-three residents (60.5\%) were Caucasian, 12 (31.6\%) were African American, and the remaining 3 represented other ethnicities, including Hispanic Americans. Over half of the sample (55\%) reported their health as good. Twenty-five older adults (66\%) mentioned that the relocation was anticipated and prepared for over time. The scores reflecting environmental changes ranged from 1 (no different) to 10 (very different), with a mean of 7.4 (SD = 2.5), indicating above-moderate environmental change.

\section{Evaluation of Intervention Parameters}

\section{Necessity}

Baseline resourcefulness scale scores were examined to indicate level of need for RT; elders who completed the RT were later asked about their perceived need and the need of others like them for RT. Baseline resourcefulness scores were normally distributed with $76.3 \%(n=29)$ of the older adults scoring below 120, indicating a strong need for RT. Two participants dropped out of the study (one from the control group and one from the RT group), leaving 38 elders who completed the RT intervention. The elder who dropped out of RT attended three sessions and then was referred to Hospice; she did not drop out because she felt no need for RT. Of the 19 older adults who received RT, all of the non-white elders $(n=5)$ reported a felt need for RT, while $43 \%$ of white elders $(n=6)$ reported a need for RT. Further, $90 \%(n=17)$ believed that older adults like them who relocated to retirement communities, might need RT. They noted that relocated older adults would want this intervention to help them be independent in finding and using the resources. One older adult said, "One of the salesmen told me about a woman who didn't leave her room because she didn't think she could make it to the elevator. When they found out, they moved her. You're dependent here, but you 
also have to be independent about things." Participants also commented that the intervention "gives them hope for the future if they have a problem;" "they discover more in their life;" and "it keeps your mind going, involved with people."

\section{Acceptability}

When asked what part of the intervention was most interesting, 42\% $(n=8)$ of the intervention group ( $n=19)$ mentioned "learning about the experiences of others/listening." One participant mentioned that the most interesting part of the intervention was, "I guess probably the bits and pieces of peoples" lives and how they handled problems." Other participants said, "you learn things you don't know about other people," "listening to the other people," "finding out what others are going through," and "hearing reactions to the questions that ... [the leader] asked ... I thought it was kind of amazing some of the answers."

The other most interesting part of the intervention, according to the elders, was "discussion," which was mentioned by $21 \%(n=4)$ of the group. One elder said, "I think there were a couple of people who were having a problem. I think it was interesting when we approached that and tried to help them." Another said, "When talking about ourselves and discussing with one another, it brought us closer."

When asked what part of the intervention was least interesting, 16\% ( $n=3)$ mentioned participants who dominated the discussion in one way or another. One older adult said that the least interesting part was, "when participants dominated the discussions and talked about their personal lives."

Another said, "One person talked too much. One person kept bringing up their past and didn't want to solve her problems." Another two mentioned, "loss of focus in discussion/repetition" as the least interesting part of the discussion, and one said, "[Individual] kept repeating the same thing and we already heard it before." About 63\% $(n=12)$ mentioned that the intervention was interesting and that they did not think any of it was uninteresting. Older adults said, "I can't think of anything that was not interesting;" "It's interesting to get other people's opinions on different subjects;" "I thought it was all interesting;" "I thought the idea was wonderful;" and "I liked it all. I thought it was good;" Older adults mentioned that using the group format was beneficial in providing support to each other: "It's kind of a support group, I think it's really good," and in helping them express their emotions: "can get a lot off their chest by talking" and "Well, in our group there were several who benefited by talking over their problems."

\section{Feasibility}

About 26\% $(n=5)$ mentioned that nothing about the intervention was difficult. Approximately $32 \%(n=$ 6) said that talking and sharing their experiences with the group was the easiest part of the intervention. One mentioned, "When we all talked about our experiences ... just relaying to other people what we felt about different things ... talking and have round table discussions was the easiest part for me." Twenty-one percent $(n=4)$, however, mentioned that talking and sharing feelings were the most challenging part of the intervention. One said, "I'm not a talker;" another added, "explaining feelings." Another $21 \%$ mentioned "monopolization of conversation by a participant" as the most challenging part of the intervention. About $16 \%(n=3)$ said that "nothing was challenging. No one complained about the number and the length of sessions. Almost all ( $n=17)$ attended all the sessions; only two participants missed one session. 


\section{Fidelity}

Approximately 95\% $(n=18)$ said that they were able to learn all parts of the intervention. One said:

We went through the whole thing. I thought that was great. I probably will never forget that. Rely on, seek professional help, organize your day, use positive self-talk, reframe situations.

When asked what might have helped them to learn better, 68\% $(n=13)$ mentioned that nothing more was needed. They said, "I can't think of anything" and "I don't know. I just thought it was interesting." Two mentioned that it would be better if there was "a stronger leader to keep the group on track" and another commented that "[the leader] ... didn't have control of the group. She let this one woman go on and on instead of keeping us on track." Another two mentioned that it would be helpful if they had written materials: "If I would have been more adept with my hands, I would have taken notes of sayings or words of wisdom."

\section{Safety}

Approximately $53 \%(n=10)$ mentioned that nothing was uncomfortable. Around $21 \%(n=4)$ mentioned that a participant caused discomfort in the group by monopolizing the discussion. One older adult said, "That woman made it uncomfortable. Other than that, nothing was uncomfortable about the whole program." Another added, "We had one woman who annoyed me a little because she monopolized the conversation, but I didn't feel uncomfortable." Around 21\% $(n=4)$ mentioned that they felt uncomfortable when they listened to the experiences of others and felt they wanted to help but could not help that much. Many of the residents said that they enjoyed the sessions and the refreshments helped them to take a break and to socialize.

\section{Effectiveness}

Effectiveness was assessed by asking the participants what part or parts of the intervention were most and least useful in helping them cope with their relocation. They also were asked to describe how the intervention could be improved. Twenty-six percent $(n=5)$ said that learning about resources and how to seek and use available resources were most helpful. One mentioned "learning new sources of information and help for the folks that just came here. For example, I didn't know the Department of Aging and that there was transportation available besides what is offered here." Two other adults said, "the positive thinking and being able to think on your own and do something about them; not just complain about it. Find a resource and take care of your problem," and "dealing with things, how to focus on the positive. Alternatives for seniors/older people." Around 47\% $(\underline{n}=9)$ mentioned that hearing the experiences of others and the information gained during the sessions were most helpful. One said, "listening to others' problems and realizing mine are not as bad."

When participants were asked about what part of the intervention was least helpful, all but three said nothing was least helpful. Those three said it was least helpful when members "went off the topic" and repeated what had been already said. Finally, we asked participants how we could make the intervention better. About 74\% $(n=14)$ mentioned that no changes were needed. Sixteen percent $(n=$ 3) said the intervention would be better if the group was kept on track. One older adult commented, "People didn't stay on the subject, they wandered." Eleven percent $(n=2)$ mentioned that it would be helpful to set specific topics to discuss, noting that "perhaps, a little organization or set things to talk 
about. This was broad." When we asked if there was anything else they wanted us to know, no further suggestions were offered and many commented that the intervention had worked really well.

\section{DISCUSSION}

This study is the first to evaluate the necessity, acceptability, feasibility, safety, fidelity, and effectiveness of a resourcefulness training intervention designed to help older adults adjust to relocation. Of primary interest was the perspective of the older adults who took part in the intervention in terms of their views on the intervention parameters. It is vital to assess all of these parameters when developing interventions; for example, the importance is questionable, if an intervention is found effective but the recipients do not believe it is needed (Zausnziewski, 2012).

This study suggested that there is a strong need for resourcefulness training among relocated elders, as indicated by resourcefulness scores: $76.3 \%$ of older adults scored less than 120 . All of the non-white elders reported a felt need for RT, while $43 \%$ of the white elders reported a need for RT. These results, suggest that non-white elders might need the intervention more than white elders. Future studies should compare the necessity of the intervention in larger samples of whites and non-whites.

In terms of acceptability, the participants indicated that "learning about the experiences of others/listening" and "discussion" were the most interesting parts of the intervention. The least interesting part of the intervention was another "participant dominating discussion" and "loss of focus in discussion/repetition." Future research might consider allowing only five minutes at a time for each participant, and making this clear at the beginning of each session, thus giving every older adult an opportunity to participate and to refocus the sessions when elders get off topic.

Fidelity of the intervention was assessed by asking the participants whether they believed they had learned all the skills constituting resourcefulness training and what might have helped them to learn these better. Approximately $95 \%$ mentioned that they were able to learn all parts of the intervention; $10.5 \%$ mentioned that it would be better with "a stronger leader to keep the group on track" and another $10.5 \%(n=2)$ said that it would be helpful to have written materials. Future studies might consider distributing handouts at the end of each session.

Safety of the intervention was assessed by asking the older adults what part(s) of the intervention were most and least distressing or uncomfortable and if they had any concerns about confidentiality during the group interactions. Approximately 53\% mentioned that nothing was uncomfortable but $21 \%$ mentioned that a participant caused discomfort in the group by monopolizing the discussion. Another $21 \%$ said that they felt uncomfortable when they listened to the experiences of others and wanted to help but could not. Future studies might consider more reflection and expression of feelings regarding the issues that might cause discomfort to older adults. The qualitative findings from this pilot intervention study on the resourcefulness intervention parameters will inform future, larger clinical trials to help recently relocated elders adjust to relocation.

Acknowledgement: This research was funded by a Sigma Theta Tau International Small Grant award. The authors acknowledge the editorial assistant of Elizabeth Tornquist of the University of North Carolina at Chapel Hill. 
Declaration of interest: The authors report no conflicts of interest. The authors alone are responsible for the content and writing of the paper.

\section{REFERENCES}

Ayers, C. R., Sorrell, J. T., Thorp, S. R., \& Wetherell, J. L. (2007). Evidence-based psychological treatments for late-life anxiety. Psychology and Aging, 22(1), 8-17.

Bekhet, A., Zauszniewski, J. A., \& Nakhla, W. (2009, June). Reasons for relocation to retirement communities: A qualitative approach. Western Journal of Nursing Research, 31(4), 462-479.

Bekhet, A., Zauszniewski, J.A, \& Wykle, M. (2008, February). Midwest Nursing Research Society Sage Best Paper Award: Milieu change and relocation adjustment in elders. Western Journal of Nursing Research, 30(1), 113-129.

Chao, S., Hagsavas, V., Mollica, R., \& Dwyer, J. (2003). Time for assessment of nutrition services in assisted living facilities. Journal of Nutrition for the Elderly, 23(1), 41-54.

Glaser, B. G. (1992). Basics of grounded theory analysis. Mill Valley, CA: Sociology Press.

Griffith, L., Raina, P., Wu, H., Zhu, B., \& Stathokostas, L. (2010). Population attributable risk for functional disability associated with chronic conditions in Canadian older adults. Age and Aging, 39(6), 738-745.

Guba, E. G., \& Lincoln, Y. S. (1989). Fourth generation evaluation. Newbury Park, CA: Sage.

Miller, M. D. (2008). Using interpersonal therapy with older adults today and tomorrow: A review of the literature and new developments. Current Psychiatry Report, 10(1), 16-22.

Musil, C. M., Haug, M. R., \& Warner, C. D. (1998). Stress, health, and depressive symptoms in older adults at three time points over 18 months. Issues in Mental Health Nursing, 19, 207-224.

Nadler, A. (1990). Help-seeking behavior as a coping resource. In M. Rosenbaum (Ed.), Learned resourcefulness: On coping skills, self-control, and adaptive behavior (pp. 127-162). New York, NY: Springer.

Streubert, H. J., \& Carpenter, D. R. (1999). Qualitative research in nursing: Advancing the humanistic imperative. Philadelphia: Lippincott Williams \& Wilkins.

National Center for Chronic Disease Prevention and Health Promotion. (2011). Healthy aging: Helping people to live long and productive lives and enjoy a good quality of life. Retrieved from http://www.cdc.gov/chronicdisease/resources/publications/aag/pdf/2011/Healthy Aging AAG 508.pdf

Pfeiffer, E. (1975). A short portable Mental Status Questionnaire for the assessment of organic brain deficit in elderly patients. Journal of the American Geriatric Society, 23, 433-441.

Rosenbaum, M. (1990). Learned resourcefulness: On coping skills, self-control, and adaptive behavior. New York, NY: Springer.

U.S. Department of Health and Human Services, Administration on Aging. (2011). Aging statistics. Retrieved from http://www.aoa.gov/aoaroot/aging statistics/index.aspx

Van't Veer-Tazelaar, P. J., van Marwijk, H. W., van Oppen, P., van Hout, H. P., van der Horst, H. E., Cuijpers, P., Smit, F. (2009). Stepped-care prevention of anxiety and depression in late life: A randomized controlled trial. Archives of General Psychiatry, 66, 297-304.

Wilkinson, P., Alder, N., Juszczak, E., Matthews, H., Merritt, C., Montgomery, H., Howard, R. (2009). A pilot randomised controlled trial of a brief cognitive behavioral group intervention to reduce recurrence rates in late life depression. International Journal of Geriatric Psychiatry,24(1), 6875.

Wolff, J. L., Boult, C., Boyd, C., \& Anderson, G. (2005). Newly reported chronic conditions and onset of functional dependency. Journal of the American Geriatrics Society, 53(5), 851-855. 
Zauszniewski, J. A. (1997). Teaching resourcefulness skills to older adults. Journal of Gerontological Nursing, 23(2), 14-20.

Zauszniewski, J. A. (2006). Resourcefulness: A new mid-range theory. In J. J. Fitzpatrick \& M. Wallace (Eds.), Encyclopedia of nursing research (pp. 256-258). New York, NY: Springer.

Zauszniewski, J. A. (2012). Intervention development: Assessing critical parameters from the intervention recipient's perspective. Applied Nursing Research, 25(1), 31-39.

Zauszniewski, J. A., \& Bekhet, A. (2011). Measuring use of resourcefulness skills: Psychometric testing of a new scale. International Scholarly Research Network Journal. doi: 10.5402/2011/ 787363

Zauszniewski, J. A., Eggenschwiler, K., Preechawong, S., Roberts, B. L., \& Morris, D. L. (2006). Effects of teaching resourcefulness skills to elders. Aging \& Mental Health, 10(4), 404-412.

Zauszniewski, J. A., Lai, C. Y., \& Tithiphontumrong, S. (2006). Development and testing of the resourcefulness scale for older adults. Journal of Nursing Measurement, 14(1), 57-68. 